\title{
OS CONTRATUALISTAS E A FORMAÇÃO DO ESTADO MODERNO
}

\section{CONTRACTUALISTS AND MODERN STATE FORMATION}

\section{Williem da Silva Barreto Júnior ${ }^{1}$ \\ Sérgio Urqhart de Cademartori²}

\section{RESUMO}

O presente artigo tem por objetivos: a) apresentar as principais teorias sobre o contrato social, protagonizadas por Thomas Hobbes, John Locke e Jean-Jacques Rousseau, sob um prisma comparativo; e b) analisar os antecedentes, implicações e peculiaridades do estado moderno, contextualizando-o histórica, política e juridicamente. Em sentido conclusivo, sustenta-se a relevância dos teóricos contratualistas para a estruturação do novel arquétipo estatal e a superação da noção patrimonialista de estado, que abriu espaço para a emergência da coisa pública. Para tanto, a pesquisa é feita com base numa abordagem de natureza qualitativa, empregando-se a metodologia hipotético-dedutiva, em associação com o método bibliográfico, através do qual são analisados livros, artigos científicos e teses de prestígio junto à comunidade acadêmica.

PALAVRAS-CHAVE: Contratualismo; Estado moderno; Jean-Jacques Rousseau; John Locke; Thomas Hobbes.

\section{ABSTRACT}

This present article aims to: a) present the main theories on the social contract, led by Thomas Hobbes, John Locke and Jean-Jacques Rousseau, from a comparative perspective; and b) analyze the background, implications and peculiarities of the modern state contextualizing it historically politically and legally. In a conclusive sense the relevance of the contractual theorists

\footnotetext{
1 Advogado. Mestrando em direito pela UNIFG/BA. E-MAIL: williem.adv@hotmail.com. ORCID: 00000002-3519-7793 ENDEREÇO DE CONTATO: rua Sinhazinha Santos, 237, sala 01, centro, Vitória da Conquista, Bahia, CEP 45000-505

2 Professor do PPGD da UNIFG/BA. Doutor em direito pela UFSC. E-MAIL: sucademartori@gmail.com ORCID: 0000-0002-2037-1496 ENDEREÇO DE CONTATO: Avenida Victor Barreto, 2288, centro, Canoas/RS, CEP 92010-000
} 
for the structuring of the novel state archetype and the overcoming of the patrimonialist notion of the state which opened space for the emergence of public affairs is sustained. To this end the research is based on a qualitative approach using the hypothetical-deductive methodology in association with the bibliographic method through which books scientific articles and prestigious theses are analyzed with the academic community.

KEYWORDS: Contractualism; Modern State; Jean-Jacques Rousseau; John Locke; Thomas Hobbes.

\section{INTRODUÇÃO}

O surgimento do estado moderno é fenômeno relativamente recente e, como todo evento histórico relevante, não ocorreu de modo descontextualizado. Pode-se afirmar que houve, anteriormente, diversas formas de organização político-jurídica similares a arquétipos estatais, como a polis grega, as cidades romanas e os feudos característicos da idade média, embora não se tenha consenso a respeito de estes terem sido ou não estados.

A partir do século XV, mudanças estruturais, ocorridas na Europa, sinalizaram a decadência do modo de produção servil predominante no medievo, ocasião em que o capitalismo mercantil galgou protagonismo econômico, inicialmente na Inglaterra, França, Portugal e Espanha, até expandir-se, não muito tempo depois, para a totalidade do continente europeu.

Com efeito, postula-se discutir as ideias dos principais teóricos contratualistas relativas à vida humana em comunidade, anterior e posteriormente ao firmamento do pacto social, e como elas concorreram para a estruturação do estado moderno. Buscase, ainda, discorrer especificamente acerca do estado moderno, seus antecedentes e peculiaridades.

A problematização reside na necessidade de se investigar, com o devido rigor, a repercussão das teorias contratualistas no modelo sucessor da organização feudal predominante na idade média. Daí se extrai a relevância da pesquisa, por contribuir para um melhor entendimento sobre o estado de direito na atualidade, na medida em que analisa um ancestral seu - o estado moderno -, e as ideias que o fundamentaram. 
Para tanto, emprega-se a metodologia hipotético-dedutiva. Partindo-se do problema, é possível conceber, como hipóteses possíveis: a) ter havido ou não influência das teorias contratualistas na formação do estado absolutista; b) os eventos históricos, implicadores do surgimento do estado moderno, ou foram aleatórios ou se conectaram com interesses da burguesia ascendente. Com base na exploração do referencial teórico, as hipóteses serão naturalmente falseadas/confirmadas, o que direcionará a conclusão da pesquisa.

O desenvolvimento do artigo está dividido em dois capítulos. No primeiro, discorre-se sobre as ideias de Thomas Hobbes, John Locke e Jean-Jacques Rousseau, a respeito de temas que gravitam fundamentalmente em torno dos conceitos de estado de natureza e pacto social. Já no segundo, considerada a influência de cada um dos autores anteriormente analisados, busca-se compreender como se deu a formação do estado moderno, suas implicações históricas, políticas e jurídicas correlatas.

\section{AS PRINCIPAIS TEORIAS CONTRATUALISTAS: CONTRIBUIÇÕES DE HOBBES, LOCKE E ROUSSEAU}

O contratualismo moderno ${ }^{3}$ se apresentou ao mundo entre os séculos $\mathrm{XVI}$ e $X V I I I$, e teoricamente se ancorou na dicotomia entre estado de natureza e estado civil, intermediada pelo contrato social. Com base nessa linha compreensiva, os seres humanos, inicialmente insertos no contexto primitivo do estado de natureza, passaram ao estado civil, por meio do firmamento de um pacto de dimensões coletivas ${ }^{4}$.

\footnotetext{
${ }^{3} \mathrm{O}$ contratualismo fundamentou o surgimento do estado através de um contrato, artificial e consensualmente instituído pelos homens. Os seus teóricos mais proeminentes foram: Thomas Hobbes, John Locke e Jean-Jacques Rousseau. Para um melhor entendimento, envolvendo as diversas teorias contratualistas, recomenda-se a leitura de: HOBBES, Thomas Leviatã ou Matéria. Forma e Poder de um Estado Eclesiástico e Civil. São Paulo: Martins Fontes, 2003; LOCKE, John. Segundo tratado sobre o governo civil. São Paulo: Abril cultural, 1983; e ROUSSEAU, Jean-Jacques. Contrato social. São
} Paulo: Abril cultural, 1983.

${ }^{4}$ Ver PASOLD, César Luís. A função social do estado contemporâneo. Florianópolis: Editora do autor, 1984. 
DOI 10.20873/uft.2359-0106.2021.v8n2.p221-240

Os teóricos contratualistas se debruçaram sobre o fenômeno da origem do estado moderno ${ }^{5}$, cuidando de fundamentar o poder político como decorrência de um acordo social de vontades, que se incumbiu de promover a superação do estado de natureza, ou pré-político, e a instituição da sociedade política, ou civil. Assim, o estado civil funcionaria como uma ferramenta da racionalidade humana, para combater as típicas debilidades do estado primitivo, ora considerado hipótese lógica, ora fato histórico real (STRECK; BOLZAN DE MORAIS, 2019, p. 29).

O contrato social exsurgiu como um recurso legitimador da entidade estatal, baseando-se nas seguintes premissas: a) o estado de natureza refletia o homem e o seu convívio fora de um contexto social; b) o contrato se afigurava um instrumento emancipatório do estado de natureza e fomentador do poder político; e c) o estado civil adveio de uma concepção de racionalidade, amparada no consenso dos indivíduos que integram a sociedade (BOBBIO; BOVVERO, 1986, pp. 77-80).

Com efeito, o estado de natureza foi frequentemente aventado como mera hipótese negativa, referindo-se a projeções teóricas abstratas, cujo mote era justificar o aparecimento da sociedade política organizada. Foi concebido, outrossim, como instituto contraditório ao estado civil, não se confundindo com uma realidade selvagem, ou algo similar (STRECK; BOLZAN DE MORAIS, 2019, p. 30).

Para os teóricos contratualistas, o conceito de estado de natureza não foi uníssono. Segundo Crawford Macpherson (2011, p. 19), Thomas Hobbes ${ }^{6}$ o associou à permanente guerra, onde imperavam insegurança, incerteza e o predomínio do mais forte sobre o mais débil, daí o clássico adágio hobbesiano: "o homem é o lobo do homem" (HOBBES, 2002, p. 32). Jean-Jacques Rousseau7, contudo, descreveu o estado de natureza como a condição primitiva da humanidade, na qual havia amplas

\footnotetext{
${ }^{5}$ Em linhas gerais, surgiu, no século XV, da junção de feudos existentes no continente europeu, em razão da decadência do feudalismo e do desenvolvimento do capitalismo mercantil, observado em Portugal, França, Inglaterra e Espanha. Ver BOBBIO, Norberto; BOVVERO, Michelangelo. Sociedade e estado na filosofia política moderna. São Paulo: Brasiliense, 1986.

${ }^{6}$ Thomas Hobbes (1588-1679) foi um teórico político, filósofo e matemático inglês. Sua obra mais relevante foi "Leviatã", na qual defendeu a tese do contrato social centrada no absolutismo.

7 Jean-Jacques Rousseau (1712-1778) foi um filósofo social, político e escritor suíço. Em sua obra mais importante, "O contrato social", desenvolveu a teoria de que a soberania reside no povo.
} 
liberdade e satisfação para o "bom selvagem", conceito por ele cunhado, para qualificar o homem não civilizado (RECIO; NASCIMENTO, 2012, p. 10).

John Locke ${ }^{8}$, considerado o pai do liberalismo, descreveu o estado de natureza como o estágio social e político das sociedades (BOBBIO, 2017, p. 40), no qual havia paz relativa, caracterizada por algum grau de domínio racional sobre as paixões. Dentro dessa conjuntura, a racionalidade impunha limites às ações humanas, endossando um arquétipo de direitos naturais de espectro vinculante, tais como a vida, a liberdade e os bens (LOCKE, 1998, p. 382).

Os três contratualistas anteriormente citados explicaram o contrato social de formas diversas, inobstante todos eles tenham convergido para a necessidade de modificação dos parâmetros de convivência social, do estado de natureza para o estado civil. Com esse objetivo, os homens se reuniram e se associaram através de um pacto, responsável pela retirada da sociedade de um contexto primitivo, levando-a a um político ${ }^{9}$.

Consoante Hobbes, o pacto social foi estabelecido entre os indivíduos para assegurar as suas próprias vidas. Nesse sentido, foi necessário que ocorresse a migração dos principais poderes daqueles - os direitos só serão instituídos efetivamente com o advento do estado moderno - para uma pessoa ou assembleia delas, que estaria/estariam destinado (s) a prover a segurança de todo o corpo social, combatendo a violência desenfreada que reinava no estado de natureza (GINZURG, 2014, p. 19).

O estado foi caracterizado por Hobbes como o leviatã, ou deus mortal, ao qual a sociedade devia a paz e a defesa das vidas dos seus membros, daí porque tal definição calha com a teoria do estado hobbesiana, pois a monarquia absolutista, por ele referendada, se revelou metade monstro e metade mortal. Dessa forma, a existência do

\footnotetext{
8 John Locke (1632-1704) foi um filósofo inglês, que se destacou especialmente por seus estudos de filosofia política, sendo considerado um precursor do liberalismo e do estado de direito. Sua obra mais relevante foi "O segundo tratado sobre o governo civil".

${ }^{9}$ Ver BONAVIDES, Paulo. Teoria do estado. São Paulo: Malheiros, 1995.
} 
leviatã era crucial para o surgimento de um poder comum, apto a proteger os indivíduos de injúrias externas e desentendimentos domésticos (HOBBES, 1992, p. 108).

Nessa linha de intelecção, Hobbes referendou a supressão das vontades individuais e a sua conversão em uma única voz institucional, a partir da qual um representante, ou um corpo deles, encarnasse/encarnassem a totalidade dos componentes da sociedade. Tratava-se de algo que superava a mera concordância, chegando ao patamar de unidade real, materializada por meio de um pacto amplo, firmado entre todos os homens, sem exceção (HOBBES, 2003, p. 113).

Renato Janine Ribeiro (1999, p. 92) afirma que, para Hobbes, inclusive a propriedade poderia ser taxada ou confiscada pelo soberano, e somente por este, restando assegurado o seu legítimo exercício em relação aos súditos, sem exceção. Nessa perspectiva, rompe-se com os então vigentes modelos de servidão típicos do período pré - estatal, mediante a eliminação do controle social da propriedade e instaurando-se, sobre ela, a ingerência política do estado.

Assim, o núcleo de indivíduos de uma sociedade principiou a gravitar em torno de uma só pessoa ou grupo delas, que institucionalizou/institucionalizam a figura do estado. Este, todavia, ancorou-se em pactos recíprocos, realizados entre os membros das comunidades, que acataram a utilização de força coativa para a mantença da paz e a defesa comum. No referido contexto, o papel de concentração dos poderes outorgados pelos indivíduos coube ao soberano, sendo os outorgantes chamados de súditos ${ }^{10}$.

Segundo Bobbio (2017, p. 31), Hobbes se colocou contra a tradição histórica do jusnaturalismo ${ }^{11}$, opondo o instituto da lei civil ao da lei natural, que, por estar associado (este último) ao stato di natura, vigorava em um contexto de irrestrita insegurança para as populações. Assim, o único modo de assegurar o respeito ao pacto social seria a adoção de um stato civile, em que as regras postas pelo soberano sobressaíssem. Para Hobbes, conforme corrobora Macpherson (2011, p. 92), quanto à autopreservação

\footnotetext{
10 Ver LASTRA, Arturo Pellet. Teoría del estado. Buenos Aires: Abeledo-Perrot, 1998.

${ }^{11}$ Ver BOBBIO, Norberto. Jusnaturalismo e positivismo jurídico. São Paulo: UNESP, 2016.
} 
estatal de incursões bélicas estrangeiras e tensões internas, típicas do estado de natureza, somente seria possível manter a estabilidade institucional pela perpetuação do soberano no poder.

Novamente com Bobbio (1991, p. 43), é crível entender que, em Hobbes, para o desejado pacto de união (transição do estado de guerra para o de paz) ser instituído, a soberania do estado nacional deveria apresentar três características fundamentais: a) irrevogabilidade; b) absolutismo; e c) indivisibilidade. Sem tais elementos, não seria possível garantir a segurança dos membros do corpo social, que permaneceriam em guerra constantemente.

Locke, outrossim, sustentou que o contrato social ostentava conteúdo diverso daquele apontado por Hobbes, nada obstante o tenha considerado uma fonte inequívoca de legitimação do poder estatal. Segundo o teórico britânico, os direitos naturais limitavam os preceitos da convenção coletivamente ratificada, daí o pacto social ser afirmado apenas para consolidar os direitos anteriormente existentes, resguardando os signatários quanto a uma possível generalização de conflitos interpessoais (LOCKE, 1998, p. 495).

Os contratualistas aqui estudados também divergiram sensivelmente no tocante ao conceito do estado civil. Hobbes defendeu a instauração de um poder estatal ilimitado, destituído de interrelação com o estado de natureza, o que justificava a legitimidade do estado absoluto, no qual o príncipe pudesse agir como bem the aprouvesse, inadmitindo-se falha por sua fraqueza (GINZURG, 2014, p. 25).

Desse modo, encontram-se ausentes na teoria hobbesiana referenciais do estado de natureza para o desenvolvimento do estado moderno, pois, ao firmarem o pacto social, os indivíduos teriam renunciado a todos os seus poderes, exceto às próprias vidas, funcionando o soberano como personificação da defesa dos interesses coletivos. Tanto o estado quanto o direito desempenhavam as suas funções em adesão 
às limitações estipuladas pelo monarca, que estava desvinculado das cláusulas do contrato ${ }^{12}$.

Por seu turno, Locke sustentou que o contrato social era um insumo necessário para a superação do estado de natureza, em prol do estado civil, quando os direitos naturais pré-existentes passaram a ser institucionalmente respeitados, por influência estatal. Desse modo, o pacto deveria conter premissas relativas aos direitos naturais, responsáveis por fixar limitações à conduta do soberano, que, ao revés do observado em Hobbes, não estava irrestritamente desobrigado (LOCKE, 1998, p. 468).

Em Locke, houve antecedentes cruciais para o posterior surgimento do individualismo liberal, teoricamente vigente numa sociedade não conflituosa, controlada pelos direitos naturais pré-existentes ao firmamento do pacto social (BOBBIO, 2017, p. 157). Assim, para o cientista político inglês, não existia maneira mais eficaz para o gozo da vida e propriedade que não a criação de elos sociais, decorrentes da instituição de um contrato amplo e limitador da atuação do estado (MELLO, 2008, p. 86).

Segundo Renato Janine Ribeiro (1999, p. 82), é possível entender a importância dada por Locke à propriedade enquanto direito natural, a ponto de aquele qualifica-lo como "filosofo da propriedade". Assim, o homem lockeano é descrito como "ativo proprietário", cujos objetos de dominação devem-lhe ser integralmente atribuídos, em concordância com uma deferência de matriz divina, ou natural.

Com efeito, o aparato estatal estaria adstrito a uma dupla limitação: primeiro, pelos direitos naturais anteriores à concepção do próprio estado civil; e segundo, por sua designação de concorrer para que os endossantes do pacto deles usufruíssem. A lei civil postularia, precipuamente, reforço aos direitos naturais já existentes, de forma que os indivíduos somente abdicassem da prerrogativa de promover a justiça privada, numa linha intelectiva bastante diversa da apregoada por Hobbes (LOCKE, 1998, p. 472).

\footnotetext{
12 Ver HOBBES, Thomas Leviatã ou Matéria. Forma e Poder de um Estado Eclesiástico e Civil. São Paulo: Martins Fontes, 2003.
} 
Como o poder estatal nasceu naturalmente limitado, os equívocos eventualmente perpetrados pelo soberano poderiam decorrer da sua fraqueza, mas não do excesso, ao qual se deveria contrapor legitimamente por meio do direito de resistência (BOBBIO, 2017, p. 86). A partir de tal premissa, revela-se evidente a vinculação direta entre Locke e o individualismo liberal ${ }^{13}$, na medida em que aquele postulou a instituição de um sistema de freios e contrapesos (controle mútuo) entre os poderes legislativo, executivo e a própria sociedade civil. É possível afirmar que o contratualismo ora analisado tratou as relações sociais e políticas sob a ingerência de uma ferramenta de racionalização, o direito, este enquanto agente regulador do pacto firmado entre os integrantes da sociedade, com o fulcro de preservação das liberdades ${ }^{14}$.

Acerca da abordagem lockeana a fundamentar o desenvolvimento do capitalismo, Macpherson ${ }^{15}$ apresenta uma visão esclarecedora. Identifica o evidente contraste, na análise do teórico inglês, entre as limitações de propriedade, naturalmente imanentes à essência deste instituto em si, e a superação dos limites que se impõem na sociedade real, onde reside o impulso para a cultura capitalista, fundada na acumulação ilimitada de riqueza.

Em linhas gerais, no tocante às diferenças analíticas apresentadas pelos contratualistas aqui estudados, é crível inferir que Hobbes recomendou a renúncia ampla e irrestrita a todos os poderes pertencentes aos indivíduos, com exceção das suas vidas, em prol de um soberano garantidor da segurança coletiva. Nesse momento, para o inglês, inexistiam direitos, que só floresceram após a formalização do contrato social, quando se passou do estado de natureza para o estado civil, impondo-se a atuação de um estado absolutista, detentor de ilimitadas prerrogativas (RIBEIRO, 2017, p. 8).

Locke, todavia, entendia que a potestade estatal comportava limitação e, em caso de eventuais excessos cometidos pelo soberano, os indivíduos estariam

\footnotetext{
${ }^{13}$ Ver MACPHERSON, Crawford Brough. The political theory of possessive individualism. Hobbes to Locke. Oxford university press, 2011.

${ }^{14}$ Ver LOCKE, John. Segundo tratado sobre o governo civil. São Paulo: Abril cultural, 1983.

${ }^{15}$ Ver MACPHERSON, Crawford Brough. The political theory of possessive individualism. Hobbes to Locke. Oxford university press, 2011.
} 
autorizados a exercer o seu direito de resistência. Aqui, o conteúdo do pacto social é sobremaneira diverso, pois o teórico britânico considerava a existência de direitos naturais anteriores ao firmamento do contrato, os quais deveriam ser protegidos e referendados pelo soberano, cujas ações encontravam-se a eles adstritas (MELLO, 2008, p. 84).

Jean-Jacques Rousseau diferenciou-se sobremodo dos demais contratualistas, quando avaliou o fenômeno do contrato social, que, para ele, reclamava um necessário contexto de inserção do ser humano na comunidade. De acordo com o suíço, o instituidor do estado civil foi o primeiro indivíduo que se declarou proprietário de determinada porção de terra, nominada propriedade, não sendo confrontado pelos demais (NASCIMENTO, 2008, p. 194).

Segundo o contrato social rousseauniano, o homem foi inteiramente livre enquanto vivenciou o estado de natureza, permitindo-se aprisionar a posteriori, com a sua inserção no estado civil. Desse modo, a transição do estágio natural, para o estágio político, alterou significativamente a conduta humana, instituindo, em seu universo, padrões morais que não integravam o cotidiano das sociedades primitivas ${ }^{16}$.

Para Rousseau, a desigualdade adveio da propriedade privada, que esteve intrinsecamente relacionada às constantes hostilidades, havidas entre os indivíduos, após o marco de sua instituição (ROUSSEAU, 1999, p. 87). Ao contrário da compreensão hobbesiana, sobre o homem ser o lobo do homem, o suíço julgava que o ser humano se tornou o seu próprio algoz no decorrer da história, em especial após a naturalização da posse pessoal de patrimônio (ROUSSEAU, 1983, p. 184). Contudo, inobstante o estado civil tivesse acarretado a diminuição de vantagens que a natureza propiciava ao "bom selvagem", referido processo também trouxe consigo compensações, relacionadas à ampliação das faculdades mentais humanas, ao desenvolvimento do seu raciocínio e ao enobrecimento da sua alma (REALE; ANTISERI, 1995, p. 635).

${ }^{16}$ Ver ROUSSEAU, Jean-Jacques. Contrato social. São Paulo: Abril cultural, 1983. 
De acordo com o pensamento rousseauniano, a legitimação do poder derivava da vontade geral da sociedade, que, sendo a verdadeira propulsora da vida social, estava apta a gerir as forças do estado, segundo a finalidade da sua concepção: o bem comum. Tendo as sociedades civilizadas advindo da oposição entre interesses privados, as vinculações sociais equivaleriam à tradução do conteúdo necessariamente comum a eles, afinal, acaso não houvesse algum grau de concordância, a sociedade não seria formada (STRECK; BOLZAN DE MORAIS, 2019, p. 39).

A vontade geral, para Rousseau, não se originou a partir de um pacto coletivo, que preceituava a submissão das sociedades a um soberano, mas da união entre os seres humanos, na condição de iguais entre si. Com efeito, cada indivíduo deveria renunciar aos seus interesses em prol de um projeto coletivo, de modo que o contrato social funcionasse como um consagrador do interesse público, em detrimento de aspirações privadas (MONTEAGUDO, 2010, p. 63).

Então, a soberania migraria da figura do monarca para o domínio integral do povo, sendo limitada pelos termos do contrato social inicialmente firmado, que estabeleceu parâmetros de racionalidade sobre os quais aquela amparou-se. A vontade geral deveria funcionar, nesse contexto, como um código de moralidade, relativo à obediência ao pacto como exercício de liberdade, sob a regência das leis (ROUSSEAU, 1983, p. 32).

Ainda com Rousseau, tem-se que o estado representava diretamente a consciência pública, à qual o homem devia estrita observância, eliminando-se a protagonismo de consciências privadas, por estas representarem prejuízo ao bom convívio social. Nessa linha intelectiva, para que o contrato social rousseauniano fosse exitoso, impunha-se, ao corpo social, o exercício de uma legítima coação sobre indivíduos detratores das deliberações coletivas ${ }^{17}$.

Em resumo, a vontade geral, encarnada no estado, deveria sufocar a eventual prevalência de aspirações pessoais, absorvendo-as e rechaçando-as coercitivamente,

\footnotetext{
17 Ver NASCIMENTO, Milton Meira do. Rousseau: da servidão à liberdade. In: Os clássicos da política, org. Francisco C. Weffort, Ática, São Paulo 2008.
} 
se preciso, pelo bem comum. Tal entendimento, que se propunha a retirar o poder de um príncipe ou oligarquia, e o outorgar aos indivíduos enquanto titulares de direitos coletivos, redundaria, segundo Rousseau, num estado civil compatível com as premissas da liberdade e igualdade entre os homens (RIBEIRO, 2017, p. 19).

\section{O ESTADO MODERNO: ANTECEDENTES, PECULIARIDADES E IMPLICAÇÕES}

O estado moderno, como contraponto ao modelo de organização política medieval, possuía as seguintes peculiaridades: a) território e povo; b) governo, poder e autoridade; e c) finalidade que justificasse a sua existência. Surgiu, enquanto estado unitário, dotado de uma potestade própria, na segunda metade do século $X V$, na França, Inglaterra e Espanha, expandindo-se, posteriormente, para outros países europeus. Desde a sua ascensão, revelou-se diverso de arquétipos estatais anteriores, como os presentes na Grécia, em Roma e no feudalismo (GRUPPI, 1980, p. 8).

A primeira relevante especificidade do estado moderno foi a autonomia, elemento viabilizador da afirmação da sua autoridade, independentemente de quaisquer outras. A segunda residiu na diferenciação entre a instituição estado e a sociedade civil, reforçada no século XVII, sobretudo na Inglaterra, a partir da ascensão da burguesia. Outra importante característica do estado moderno promoveu um corte paradigmático em relação à forma de organização estatal vigente na idade média, onde o arquétipo de estado tinha natureza patrimonial, por literalmente pertencer aos senhores feudais. Outrossim, durante a prevalência do arcabouço estatal moderno, operou-se uma íntima interrelação entre o estado e a esfera pública, em oposição à anterior lógica privada (HABERMAS, 1984, p. 14).

O termo estado foi cunhado por Nicolau Maquiavel, em sua clássica obra, "o príncipe", posteriormente ao ocaso do feudalismo (BOBBIO, 1987, p. 65). Há quem entenda a palavra estado como uma nova definição, usada para designar conjuntura política diversa de todas as outras, daí porque somente uma inédita nomenclatura 
poderia classificar adequadamente tão expressiva alteração na forma de organização das sociedades pós-idade média ${ }^{18}$.

O estado moderno foi fruto, portanto, de um contexto historicamente descontínuo, em especial pelo exercício de autoridade una sobre territórios vastos, a partir do monopólio de alguns serviços essenciais, dentre os quais encontrava-se a produção do direito, através da lei, emanada do estado e imposta por meio de um aparato coercitivo, em contraponto ao que ocorria no medievo (ZAGREBELSKY, 2002, p. 11).

Com Bobbio (1986, p. 131), pode-se afirmar que o conceito da comunidade política, desde a polis grega ao estado moderno, está intimamente relacionado, como contraponto ao stato di natura, à compreensão de um todo que impõe a união de partes que, num contexto diverso, quedaria em permanente conflito mútuo. Assim, o que garante a unidade do todo é a lei, que é instituída a partir da atuação do soberano.

Tomando por referências o emergente aparato burocrático e a monopolização de funções administrativas, essenciais à unidade territorial, é crível sustentar que, anteriormente - na antiguidade e idade média-, o termo estado deve ser utilizado com cautela ${ }^{19}$. Milita a favor da tese da descontinuidade histórica, na sucessão de modelos estatais, o fato de não ter havido, por exemplo, um fio condutor entre o surgimento das cidades romanas e medievais, e entre estas e as integrantes do estado moderno.

No estado moderno, o poder foi elevado ao patamar de instituição, com potência superior àquela característica do indivíduo. Com efeito, materializou-se a despersonalização da autoridade, que, inobstante impessoal, reclamava titularidade para o seu exercício, cabendo ao ente estatal o referido papel. Nesse sentido, em oposição ao arcabouço de organização política medieval, baseado na atuação

\footnotetext{
18 Ver BURDEAU, Georges. O estado. Póvoa de Varzim. Publicações Europa-América, sd.

${ }^{19}$ Ver BOBBIO, Norberto. Estado, governo e sociedade - Para uma teoria geral da política. Rio de Janeiro: Paz e terra, 1987.
} 
patrimonialista de membros da nobreza, o estado moderno se identificava com o monarca, concedendo-Ihe a prerrogativa de guardar a soberania ${ }^{20}$.

Entre $o$ arquétipo estatal predominante na idade média e o estado absolutista, tido como o primeiro gênero de estado moderno stricto sensu, houve uma transição, ocasião em que emergiu o chamado estado estamental, marcado pela concentração do poder político nos âmbitos da alta e baixa nobreza, além do clero e da burguesia urbana ascendente. Essa forma de organização transitória fundou-se em pactos subscritos por integrantes de diversos estamentos, que, leais entre si, firmaram compromisso com príncipes e reis (LASTRA, 1998, p. 34).

Esse inovador formato de organização política, para atingir o patamar dos grandes estados nacionais, concebidos posteriormente, necessitou de um reforço da sua potência, ou capacidade de imposição de obediência aos súditos, por via da autoridade, que o habilitou dar ordens legitimamente. $O$ processo de transição entre o feudalismo e o modelo dos estados nacionais implicou na transferência das relações de poder, dos senhores feudais para o âmbito público, materializado pela figura do estado (BONAVIDES, 1995, p. 77).

Bobbio tratou da ascensão do direito público enquanto elemento integrador dos estados nacionais:

Uma das características da doutrina do estado que terminou por prevalecer é o primado do direito público e, consequentemente, a declarada impossibilidade de compreender as relações de direito público através do recurso às tradicionais categorias do direito privado. Exemplar deste ponto de vista a posição de Hegel, segundo a qual as principais categorias do direito privado, a propriedade e o contrato, são insuficientes para tornar compreensível a realidade do direito público que preside à organização da totalidade, enquanto o direito privado se ocupa da resolução de conflitos entre partes independentes que assim permanecem não obstante os vínculos jurídicos, ao menos formalmente iguais (BOBBIO, 1986, p. 132). 
No medievo, a potestade política se encontrava sob o domínio de particulares, confundindo-se com o poder econômico, enquanto, no estado moderno, cristalizou-se a separação entre eles e se concebeu, pela primeira vez, a dicotomia entre espaços públicos/privados e sociedade civil/sociedade política. Com efeito, inexiste dúvida de que o marco para o surgimento do estado moderno foi a dissociação havida entre as funções administrativas/políticas e a sociedade civil (ROTH, 1996, p. 24).

Para a ascensão de um novo modo de produção, posteriormente intitulado de capitalismo, era premente a necessidade de se estabelecer um conjugado de normas gerais e impessoais, como sinônimo de segurança aos súditos - mais especificamente à burguesia -, que ansiava produzir e comercializar produtos sem ingerências externas de cunho privado, fortemente presentes na vigência da idade média (TAVARES, 1982, p. 56). Esse processo decorreu da necessidade de a burguesia, classe já dominante economicamente, consolidar o seu poder a partir da superação de um sistema contrário aos seus interesses político-econômicos.

É razoável sustentar que o conceito de estado moderno se ancorou em três fundamentos básicos: a) centralização e concentração de poder; b) igualdade abstrata entre os súditos, em supressão à estrutura anterior, fundada em castas; e c) isolamento do poder estatal em relação à sociedade civil. Seguido o caminho natural, foram sequencialmente criadas instâncias de poder mais específicas, a fim de se exercer o monopólio estatal alusivo aos sistemas monetário, fiscal e de justiça ${ }^{21}$.

A primeira versão de estado, embasada na ideia de soberania, levou à concentração de todos os poderes públicos nas mãos dos reis, originando-se as monarquias absolutistas, que se apoderaram do aparato estatal, de modo similar (não igual) à ação do proprietário em relação um objeto de sua propriedade. Esse fenômeno decorreu da necessidade de se assegurar que, no período transitório entre o feudalismo e o estado moderno, fosse possível manter a unidade dos estados nacionais, impondose a preservação dos seus territórios (BOBBIO, 1986, pp. 1-7).

${ }^{21}$ Ver TAVARES, José Antônio Giusti. A estrutura do autoritarismo brasileiro. Porto Alegre: Mercado aberto, 1982. 
Os monarcas absolutistas extraiam a sua legitimação da divindade, daí os reis serem considerados representantes de deus na terra, o que naturalmente thes desvinculava de eventuais limites impostos à sua autoridade. Com efeito, o estado absoluto fundou-se, em linhas gerais, na burocracia e, principalmente, no exército, responsável por manter as unidades territoriais durante séculos ${ }^{22}$.

Observa-se, nesse contexto, a superação do modelo carismático de dominação, então transformado num padrão racional-legal (WEBBER, 1983, p. 128), ou seja, o arquétipo estatal deixa de ser inteiramente privado, e passa a ter feições públicas, uma realidade que marca fortemente a derrocada da nobreza e a ascensão da burguesia, que posteriomente assumiria também o controle político dos principais estados europeus.

\section{CONSIDERAÇÕES FINAIS}

O estado moderno se impôs, como forma de organização política, a partir da emergência do capitalismo mercantil, que evidenciou o ocaso do modo de produção presente durante a idade média e a ascensão da burguesia como classe economicamente dominante. Esse novo paradigma histórico, para além de instituir mudanças na forma de se produzir e comercializar produtos, trouxe consigo uma nova roupagem política, através da qual o arquétipo estatal privado, pertencente aos senhores feudais, foi substituído pela coisa pública.

Referido processo foi teorizado por cientistas políticos, denominados contratualistas, dentre os quais os proeminentes John Locke, Jean-Jacques Rousseau e Thomas Hobbes. As suas ideias, acerca de temas como o estado de natureza, o estado civil e o pacto social, nada obstante divergentes entre si, foram cruciais para a estruturação e o desenvolvimento do estado como se conhece nos dias de hoje, autônomo e independente da sociedade civil, em contraponto ao modelo anterior, favorável à nobreza.

\footnotetext{
${ }^{22}$ Ver ANDERSON, Perry. Linhagens do estado absolutista. São Paulo: Brasiliense, 2004.
} 
Thomas Hobbes entendia o estado de natureza como um momento de total insegurança, em que os seres humanos, temendo ataques à sua integridade pessoal, fatalmente promoveriam ofensivas aos demais, fomentando uma guerra permanente. Desse modo, sustentou a necessidade de todos abrirem mão da totalidade dos seus poderes, exceto as próprias vidas, em favor de um indivíduo ou pequeno grupo deles, que teriam a incumbência de garantir a segurança geral, instaurando-se aí o estado civil marcado pelo absolutismo. Jà nesta época, a burguesia detinha o domínio econômico na Europa, que se seguiria também do domínio político, com o advento das revoluções liberais do século XVIII.

John Locke, tido como o pai do liberalismo, considerava a existência de direitos naturais no estado de natureza, momento em que, embora se observasse uma paz relativa, sofria-se com guerras constantes. Assim, defendeu a outorga consensual, entre os membros da comunidade, de poderes ao estado, para que este, limitado pelo conteúdo dos direitos naturais pré-existentes, agisse no sentido de promover a paz. Locke foi o grande responsável pela elevação do direito de propriedade ao patamar de direito natural inalienável e uma das bases do sistema capitalista, que se mantém até os dia de hoje.

Já Jean-Jacques Rousseau consagrou o estado de natureza como um momento de total liberdade do ser humano, em que o "bom selvagem" vivenciava uma realidade harmônica. Em sua compreensão, a desigualdade adveio do aparecimento da propriedade privada, daí o seu modelo de pacto social legitimar o poder da vontade geral da sociedade, que estaria apta a gerir as forças do estado, segundo a finalidade da sua concepção: o bem comum. Cada indivíduo deveria, então, renunciar aos seus interesses, em prol de um projeto coletivo, consagrador da coisa pública.

Sob forte influência das teorias anteriormente abordadas, pode-se afirmar que estado moderno decorreu de um processo historicamente descontínuo, pelo exercício de autoridade una sobre territórios vastos, a partir do monopólio de alguns serviços essenciais, dentre os quais encontrava-se a produção do direito, concentrada na atividade estatal. 
O poder foi alçado ao patamar de instituição e operou-se a despersonalização da autoridade, que, embora impessoal, reclamava titularidade para o seu exercício, cabendo ao ente estatal o referido papel. Com efeito, em oposição ao arcabouço de organização política medieval, baseado na atuação patrimonialista de membros da nobreza, o estado moderno se identificava com o monarca, concedendo-lhe a prerrogativa de guardar a soberania, assegurando, assim, a liberdade desejada pela burguesia para realizar os seus negócios e ampliar ainda mais o seu domínio econômico na Europa.

As profundas mudanças, anteriormente descritas, foram decorrência da emergência da burguesia, que necessitava de maior liberdade para comercializar produtos e acumular capital. A decadência do modelo servil coincidiu, nesse interim, com a derrocada econômica da nobreza, a qual não pôde resistir à pressão da classe burguesa, que fez uso da sua potência para forçar a ocorrência de rupturas políticojurídicas deveras expressivas. Conclui-se, então, que a passagem do feudalismo para o estado moderno não ocorreu por conta de eventos históricos aleatórios, mas pela prevalência de imponentes interesses político-econômicos de uma classe em ascensão, cujo domínio se mantém até a atualidade.

\section{REFERÊNCIAS}

ANDERSON, Perry. Linhagens do estado absolutista. São Paulo: Brasiliense, 2004.

BOBBIO, Norberto. Dicionário de política. Brasília: UNB, 1986.

Direito e estado em Immanuel Kant. Brasília: UNB, 1984.

. Estado, governo e sociedade: para uma teoria geral da política. Rio de Janeiro: Paz e terra, 1987.

. Jusnaturalismo e positivismo jurídico. São Paulo: UNESP, 2016.

Locke e il diritto naturale. Torino: G. Giappichelli, 2017. 
. O futuro da democracia: uma defesa das regras do jogo. Rio de Janeiro: Paz e terra, 1986.

; BOVVERO, Michelangelo. Sociedade e estado na filosofia política moderna. São Paulo: Brasiliense, 1986.

. Thomas Hobbes. Rio de Janeiro: Campus, 1991.

BONAVIDES, Paulo. Teoria do estado. São Paulo: Malheiros, 1995.

BURDEAU, Georges. O estado. Póvoa de Varzim. Publicações Europa-América, sd.

CORREA, Darciso. Implicações jurídico-políticas de dicotomia público e privado na sociedade capitalista. Tese de doutorado. Florianópolis: UFSC, 1996.

GINZURG, Carlo. Medo, reverência, terror: quatro ensaios de iconografia política. São Paulo: Companhia das Letras, 2014.

GRUPPI, Luciano. Tudo começou com Maquiavel. Porto Alegre: L\&PM, 1980.

HABERMAS, Jürgen. Mudança estrutural da Esfera Pública. Investigação quanto a uma categoria da sociedade burguesa. Rio de Janeiro: Tempo brasileiro, 1984.

HOBBES, Thomas. Do cidadão. São Paulo: Martins Fontes, 1992.

. Leviatã ou Matéria. Forma e Poder de um Estado Eclesiástico e Civil. São Paulo: Martins Fontes, 2003.

. Os Elementos da Lei Natural e Política. São Paulo: Ícone, 2002.

LASTRA, Arturo Pellet. Teoría del estado. Buenos Aires: Abeledo-Perrot, 1998.

LOCKE, John. Dois tratados sobre o governo. São Paulo: Martins Fontes, 1998.

Segundo tratado sobre o governo civil. São Paulo: Abril cultural, 1983.

MACPHERSON, Crawford Brough. The political theory of possessive individualism. Hobbes to Locke. Oxford: Oxford university press, 2011. 
MELLO, Leonel Itaussu Almeida. John Locke e o individualismo liberal. em: Os clássicos da política, (org.) Francisco C. Weffort, Ática, São Paulo 2008.

MONTEAGUDO, Ricardo. Contrato, moral e política em Rousseau. Marília: UNESP, 2010.

NASCIMENTO, Milton Meira do. Rousseau: da servidão à liberdade. em: Os clássicos da política, (org.) Franscisco Weffort. São Paulo: Ática, 2008.

PASOLD, César Luís. A função social do estado contemporâneo. Florianópolis: Editora do autor, 1984.

REALE, Giovanni; ANTISERI, Dario. Historia del pensamento filosófico y científico II. Barcelona: Herder, 1995.

RECIO, Encarnación Moya; NASCIMENTO, Paulo Roberto. Introdução a Ciências Políticas: teoria, instituições e autores políticos. São Paulo: Rede For, 2012.

RIBEIRO, Josuel Stenio da Paixão. Os Contratualistas em questão: Hobbes, Locke e Rousseau. Revista prisma jurídico. São Paulo. v. 16, n. 1, pp. 3-24, 2017.

RIBEIRO, Renato Janine. Ao leitor sem medo: Hobbes escrevendo contra o seu tempo. Belo Horizonte: UFMG, 1999.

ROTH, André-Noel. O direito em crise: Fim do estado moderno? em: FARIA, José Eduardo (org.). Direito e globalização: implicações e perspectivas. São Paulo: Malheiros, 1996.

ROUSSEAU, Jean-Jacques. Contrato social. São Paulo: Abril cultural, 1983.

- Discurso sobre a origem e os fundamentos da desigualdade entre os homens. São Paulo: Nova Cultural, 1999.

STRECK, Lenio Luiz; BOLZAN DE MORAIS, José Luís. Ciência política e teoria do estado. Porto Alegre: Livraria do advogado, 2019.

TAVARES, José Antônio Giusti. A estrutura do autoritarismo brasileiro. Porto Alegre: Mercado aberto, 1982. 
DOI 10.20873/uft.2359-0106.2021.v8n2.p221-240

ZAGREBELSKI, Gustavo. El derecho dúctil. Ley, derechos, justicia. Madrid: Trotta, 2002.

WEBBER, Max. Os três tipos puros de dominação legítima. Em: Sociologia. Gabriel Cohn (org.). São Paulo: Ática, 1986. 